\title{
The Structure of Micelles in Colloidal System of Primexine Matrix in Plants
}

\author{
S.V. Polevova
}

Higher Plants Department, Moscow State University, Leninskie gory, 1/12, Moscow, 119991, Russia

Pollen grain's cell wall posses a complex structure. A sporoderm consists of exine and intine which contains hemicellulose. The exine is formed by the sporopollenin - the most resistant natural biopolymer. Superstability of the sporopollenin makes it difficult to study its chemical structure, ways of synthesis and possible precursors. Until now the most available and effective method for studying sporopollenin remain the transmission electron microscopy (TEM). All assembly processes in the exine occur during the sporoderm development in microspores. The process of sporoderm development is divided into 2 periods called tetrad and posttetrad. During the tetrad period formation of microspore tetrads occurs, the tetrads are surrounded and protected by thick callose wall. At this time all the important events happen, among those are marking and formation of exine layers. After callose dissolves and microspores release from the tetrads, pollen grains develop (posttetrad period) and in this period they produce the intine only. The exine becomes more electron-dense and reaches its mature size.

Recently, the micellar hypothesis of self-assembly of the sporopollenin within the pollen grain wall was proposed [1]. According to this hypothesis, the self-assembly of colloidal systems appear, upon increasing the concentrations of the sporopollenin. We observed the electron light periplasmic space with the electron dense spherical granules between callose and plasma membrane in the early tetrad stages (FIG.1). This is in consistence with the hypothesis that the colloidal system in the periplasmic space of microspore forms the spherical micelles. The spherical granules are later packed in piles. With increasing concentration of sporopollenin precursors in the primexine matrix the cylindrical micelles are formed, following by the variation of the primexine pattern. At this time the connivent pairs of protobacules become visible (FIG.2). In oblique sections these structures look like rings or ovals. Thus we can conclude that the true shape of these structures is a tube. At later stages the tube cavities become narrower and then disappear completely. At this time primexine already has all the features of a mature ectexine: tectum, columellae and foot layer. At the end of the tetrad period, we have observed the electron dense lamellar micelles with so-called "white lines" (FIG.3). These lamellae later merge and form endexine, which electron density differs from ectexine, and it also contains the sporopollenin.

Four species, belonging to very different plant taxa were selected with the distinctly visible micelles of different types (TAB. 1). Variability of the diameter of spherical micelles and the diameter of cylindrical micelles in these species were well corresponded to each other. The size and shape of the micelles is probably determined by the precursors of sporopollenin concentration. This fact confirms the micellar hypothesis of self-assembly sporopollenin in exine.

\section{References}

[1] Gabaraeva N. et al., Rev. Pal. Pal. 138 (2006) 121-139.

[2] Gabaraeva N.I. et al., Grana. 49 (2010) 91-114.

[3] Gabaraeva N.I. et al., Protoplasma. 247 (2010) 65-81.

[4] This research was supported by the Russian Foundation for Basic Research under contract N10-04-00945-a. 


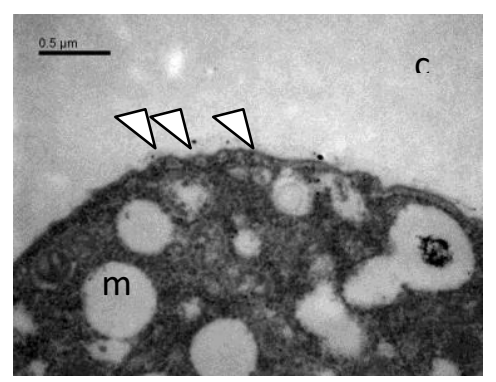

FIG.1. Nicotiana tabacum. The early tetrad stages, the spherical micelles (arrowes) in periplasmic space. $\mathrm{m}$ - microspore, $\mathrm{c}$ - callose, bar $0,5 \mu \mathrm{m}$.

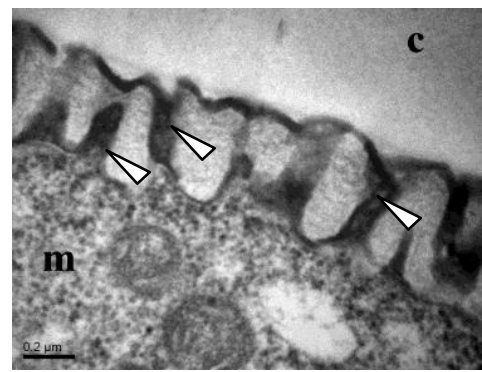

FIG.2. Nicotiana tabacum. The middle tetrad stage, the primexine with connivent pairs protobacules - cylindrical micelles (arrowes). $\mathrm{m}$ - microspore, $\mathrm{c}$ - callose, bar 0,2 $\mu \mathrm{m}$.

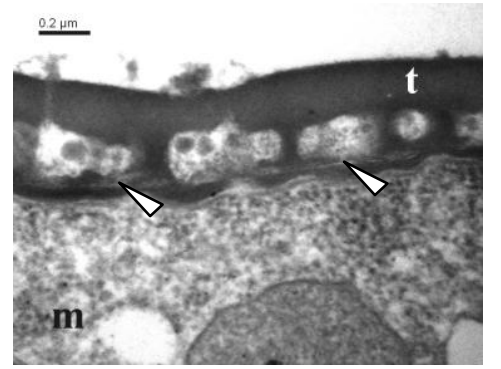

FIG.3. Nicotiana tabacum. The late tetrad stage, the electron dense lamellae of endexine with white lines - lamellar micelles (arrowes). $\mathrm{m}$ - microspore, $\mathrm{t}$ - tectum, bar 0,2 $\mu \mathrm{m}$.

TABLE 1. Mean micelles size in pollen of four species

\begin{tabular}{|c|c|c|c|c|}
\hline Species & $\begin{array}{l}\text { Clade of } \\
\text { Angiosperm } \\
\text { Tree }\end{array}$ & $\begin{array}{l}\text { Diameter }(\mu \mathrm{m}) \\
\text { spherical } \\
\text { micelles }\end{array}$ & $\begin{array}{l}\text { Diameter }(\mu \mathrm{m}) \\
\text { cylindrical } \\
\text { micelles }\end{array}$ & $\begin{array}{l}\text { Length }(\mu \mathrm{m}) \\
\text { cylindrical } \\
\text { micelles }\end{array}$ \\
\hline Acer tataricum [3] & Rosids & $0,06 \pm 0,01$ & $0,14 \pm 0,03$ & $0,30 \pm 0,04$ \\
\hline $\begin{array}{l}\text { Chamaedorea } \\
\text { microspadix [2] }\end{array}$ & Monocots & $0,04 \pm 0,02$ & $0,08 \pm 0,01$ & $0,13 \pm 0,02$ \\
\hline Nicotiana tabacum & Asterids & $0,07 \pm 0,02$ & $0,08 \pm 0,02$ & $0,27 \pm 0,05$ \\
\hline Symphytum officinale & Asterids & $0,08 \pm 0,03$ & $0,10 \pm 0,02$ & $0,10 \pm 0,02$ \\
\hline
\end{tabular}

